\title{
A Voz dos Bichos: um instituto direcionado à proteção animal e socioambiental em Porto Seguro
}

\author{
Elissandro dos Santos Santana \\ Professor da Faculdade Nossa Senhora de Lourdes \\ Membro do Grupo de Estudos da Teoria da Dependência - GETD \\ Colaborador, colunista de sustentabilidade, meio ambiente, \\ latino-americanista e tradutor do Portal Desacato \\ Revisor da Revista Latinoamérica \\ 凶 elissandross@gmail.com \\ Denys Henrique Rodrigues Câmara \\ Especialista em educação de jovens e adultos \\ Especialista em língua Portuguesa \\ Licenciado em língua portuguesa e em línguas estrangeiras modernas \\ Professor de língua inglesa do Complexo Integrado de Educação de Porto Seguro - CIEPS \\ هdenyscamara@gmail.com \\ Nicholas Lula Dias Ralile \\ Discente Pesquisador do Bacharelado Interdisciplinar em Humanidades - UFSB \\ $\square$ diasnicholas3@gmail.com \\ Radharani Cabrera Teixeira de Arruda \\ Discente Pesquisadora do Bacharelado Interdisciplinar em Humanidades - UFSB \\ $\triangle$ radha.ufsb@gmail.com
}

Recebido em 04 de março de 2017

Aceito em 26 de junho de 2017

\begin{abstract}
Resumo:
Trabalho resultante de pesquisa acerca das contribuições do Instituto A Voz dos Bichos para a proteção animal e socioambiental em Porto Seguro. Para a consecução do estudo, adotou-se um marco teórico múltiplo, alicerçado em vertentes sociais, ambientais e políticas. Para tanto, houve o aprofundamento nos estudos na área da pesquisa social, ambiental e política, partindo-se da noção de que para o estudo do fenômeno seria imprescindível um campo teórico multirreferencial. Diante de um marco nessa linha, foram apresentados alguns dos fatores e dos fenômenos da dinâmica dos projetos socioambientais. Em linhas gerais, a pesquisa foi abordada de forma qualitativo-quantitativa, com predominância da primeira sobre a segunda, servindo-se de três técnicas de pesquisa: bibliográfica, documental e de campo, com a aplicação de questionários semiestruturados para um grupo de 50 pessoas, amostra estatisticamente viável em uma população total de aproximadamente 150 mil habitantes, com vistas a captar a dimensão do Instituto em relação às mudanças sociais e culturais na perspectiva da proteção animal e socioambiental.

Palavras-chave: Instituto A Voz dos Bichos, Proteção animal e socioambiental, Sociedade, Porto Seguro.

\section{The Voz dos Bichos (Voice of Animals Institute): an NGO in the service of the protection in Porto Seguro}

\begin{abstract}
:
Work resulting from research on the contributions of The Voice of Animals Institute for animal and socio-environmental protection in Porto Seguro. To achieve the study, a theoretical framework was adopted, based on social, environmental and political aspects. For that, there was a deepening of studies
\end{abstract}


in the area of social, environmental and political research, starting from the notion that a multireferential theoretical field would be indispensable for the study of the phenomenon. Facing this milestone, some of the factors and phenomena of the dynamics of social and environmental projects were presented. In general terms, the research was approached in a qualitative-quantitative way, with predominance of the first one over the second one, being used of three research techniques: bibliographical, documentary and field, with the application of semi-structured questionnaires for a group of 50 people, a statistically feasible sample in a total population of approximately 150 thousand inhabitants, with a view to capturing the Institute's dimension in relation to social and cultural changes from the perspective of animal and socio-environmental protection.

Keywords: Instituto A Voz dos Bichos, Animal and socio-environmental protection, Society, Porto Seguro.

\title{
Instituto Voz dos Bichos (la Voz de los Animales): una ONG al servicio de la protección animal en Porto Seguro
}

\begin{abstract}
Resumen:
Trabajo resultante de investigación acerca de las contribuciones del Instituto La Voz de los Bichos para la protección animal y socio ambiental en Porto Seguro. Para la consecución del estudio, se adoptó un marco teórico múltiple, basado en vertientes sociales, ambientales y políticas. Para ello, hubo la profundización en los estudios en el área de la investigación social, ambiental y política, partiendo de la noción de que para el estudio del fenómeno sería imprescindible un campo teórico multirreferencial. Ante un marco en esa línea, se presentaron algunos de los factores y los fenómenos de la dinámica de los proyectos socio ambientales. En líneas generales, la investigación fue abordada de forma cualitativocuantitativa, con predominancia de la primera sobre la segunda, sirviéndose de tres técnicas de investigación: bibliográfica, documental y de campo, con la aplicación de cuestionarios semiestructurados para un grupo de 50 personas, muestra estadísticamente viable en una población total de aproximadamente 150 mil habitantes, con el objetivo de captar la dimensión del Instituto en relación a los cambios sociales y culturales en la perspectiva de la protección animal y socio ambiental.

Palabras clave: Instituto A Voz dos Bichos, Protección animal y socio ambiental, Sociedad, Porto Seguro.
\end{abstract}

\section{UMA CONTEXTUALIZAÇÃO NECESSÁRIA ACERCA DO INSTITUTO A VOZ DOS BICHOS}

Na Revista Ecodebate, em 2016, foi publicado um artigo acerca das contribuições socioambientais do Instituto A Voz dos Bichos para Porto Seguro e, nesta oportunidade, a discussão é retomada com o objetivo de mostrar, a partir de um ângulo mais expansivo, o papel desempenhado por esta instituição no município.

Esta ramificação da pesquisa arvorou-se no estudo e análise das contribuições da ONG para a proteção animal, o controle de zoonoses e outras problemáticas sociais e ambientais na cidade no que concerne ao bem-estar de cães, de gatos e de outros animais resgatados dos espaços públicos e influência das ações do Instituto na sociedade. Também se buscou analisar as percepções societárias acerca da cultura do abandono e opinião pública sobre a responsabilidade social-político-governamental municipal em relação aos animais. 
Para a consecução da pesquisa foi necessário um marco teórico multirreferencial, pois diante de um fenômeno com a amplitude socioambiental, que, por natureza-essência, engloba fatores sociais, culturais, ambientais e políticos, além de outros saberes, seria improdutivo alicerçar-se em perspectiva teórica unidirecional.

Em termos gerais, optou-se por uma metodologia de pesquisa qualitativoquantitativa, com predominância da primeira sobre a segunda, a partir de três técnicas de pesquisa: bibliográfica, documental e de campo, com a aplicação de questionários semiestruturados e entrevistas para 50 pessoas, grupo amostral estatisticamente viável em uma população total de aproximadamente 150 mil habitantes, segundo dados atualizados do $\mathrm{IBGE}^{1}$, com vistas a captar a dimensão do Instituto em relação às mudanças culturais e mentais na sociedade para o cuidado em relação aos animais.

Também é importante relatar que, para a análise dos dados coletados e mapeamento das ações desenvolvidas pelo Instituto, foram feitas leituras, fichamentos e anotações por meio de documentos de fundação, de regimento e de ações da ONG, além de outras informações que se fizeram necessárias.

\section{ESTRUTURA, OBJETIVOS, METAS E AÇÕES DO INSTITUTO A VOZ DOS BICHOS}

O Instituto foi fundado em 30 de abril de 2011 e é uma entidade de natureza privada, sem fins lucrativos ou político-partidários com o objetivo central de atender a todos, independente de classe social, nacionalidade, sexo, etnia, cor e/ou crença religiosa, com prazo de atuação ilimitado. É regido pelas normas transcritas em estatuto e baseia-se no tripé resgate, conscientização da população e esterilização dos animais.

As finalidades do Instituto são as que aparecem no quadro na página seguinte:

\footnotetext{
${ }^{1}$ População de Porto Seguro estimada em 2017 segundo o IBGE é de 149.324.
} 
Quadro 1 - Estrutura, objetivos, metas e ações do Instituto.

\section{Estrutura-objetivos-metas-ações}

\begin{tabular}{|c|c|}
\hline I & $\begin{array}{l}\text { Fiscalizar o cumprimento dos } \\
\text { dispositivos do Decreto Federal no } 24.645 \text {, } \\
\text { de } 10 \text { de julho de } 1.934 \text {, do artigo } 64 \text { do } \\
\text { Decreto Lei } 3.668 \text {, de } 03 \text { de outubro de } \\
\text { 1.941 (Lei das Contravenções Penais) e do } \\
\text { artigo } 32 \text { da Lei Federal no 9.605, de } 12 \text { de } \\
\text { fevereiro de } 1.998 \text { e demais leis, decretos, } \\
\text { portarias e regulamentos federais, } \\
\text { estaduais e municipais sobre a proteção } \\
\text { de animais e meio ambiente. }\end{array}$ \\
\hline II & $\begin{array}{l}\text { Reduzir a população de animais } \\
\text { abandonados, através de campanhas de } \\
\text { castração gratuitas ou de valores } \\
\text { reduzidos, principalmente, } \\
\text { comunidades carentes. }\end{array}$ \\
\hline III & $\begin{array}{l}\text { Promover campanhas de educação e de } \\
\text { conscientização, propagando a filosofia } \\
\text { do amor e do respeito aos animais, } \\
\text { incentivando a posse responsável. }\end{array}$ \\
\hline & $\begin{array}{l}\text { Dar assistência veterinária a animais de } \\
\text { pessoas carentes, abandonados, doentes, } \\
\text { feridos ou vítimas de crueldade, abuso ou } \\
\text { maus tratos, sempre que possível, de } \\
\text { acordo com a disponibilidade de } \\
\text { recursos, em clínicas veterinárias }\end{array}$ \\
\hline
\end{tabular}




\begin{tabular}{|c|c|}
\hline IV & $\begin{array}{l}\text { conveniadas, obedecidas as prescrições } \\
\text { estatutárias. }\end{array}$ \\
\hline $\mathrm{V}$ & $\begin{array}{l}\text { Recolher, sempre que possível, e de } \\
\text { acordo com a capacidade, animais } \\
\text { abandonados ou extraviados, } \\
\text { encaminhando-os, depois de tratados, } \\
\text { para a adoção, independentemente de } \\
\text { ressarcimento financeiro, a pessoas de } \\
\text { idoneidade comprovada que se } \\
\text { comprometam a dar-lhes tratamento } \\
\text { adequado e digno, mediante assinatura } \\
\text { de um termo de responsabilidade e } \\
\text { sujeito à fiscalização por parte da } \\
\text { Entidade. }\end{array}$ \\
\hline VI & $\begin{array}{l}\text { Defender o meio ambiente } \\
\text { ecologicamente equilibrado, impedindo e } \\
\text { reprimindo práticas que coloquem em } \\
\text { risco seu equilíbrio, combatendo o } \\
\text { tráfego e a extinção de animais silvestres, } \\
\text { a caça e a pesca predatórias. }\end{array}$ \\
\hline VII & $\begin{array}{l}\text { Estimular o intercâmbio e a cooperação } \\
\text { institucional e internacional. }\end{array}$ \\
\hline & $\begin{array}{l}\text { Atuar junto aos poderes públicos, visando } \\
\text { ao aperfeiçoamento e cumprimento } \\
\text { efetivo da legislação e demais } \\
\text { instrumentos de defesa do ambiente e de }\end{array}$ \\
\hline
\end{tabular}




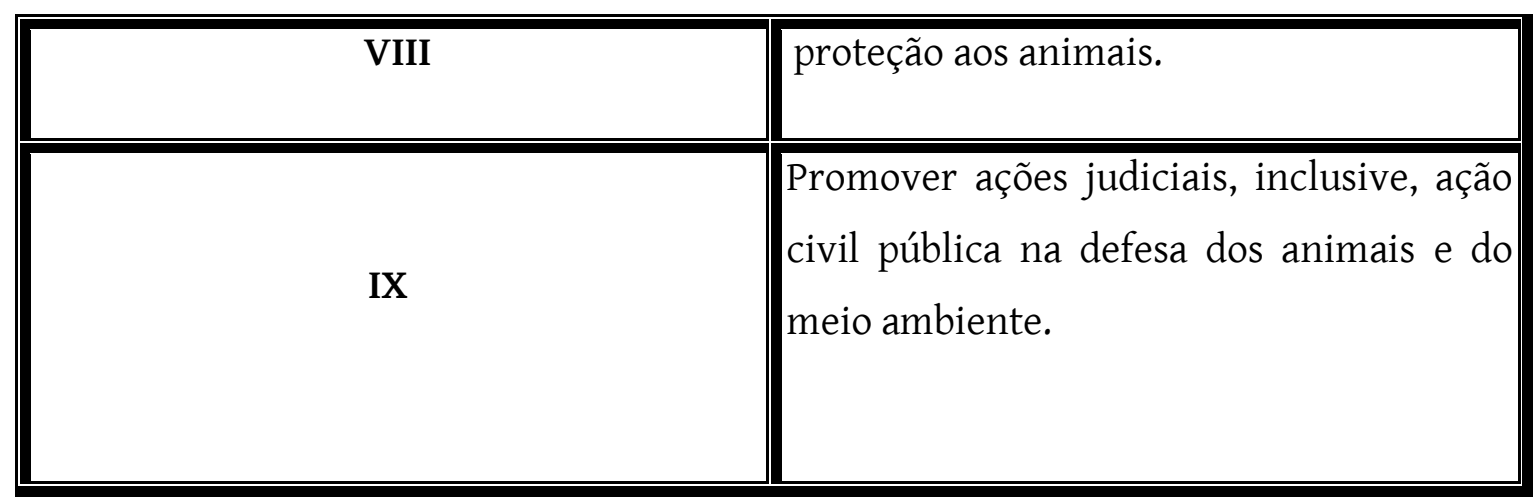

Fonte: Informações fornecidas pelo Instituto A Voz dos Bichos.

No tocante ao surgimento do Instituto A Voz dos Bichos, é importante externar que ele se originou a partir das lacunas e das ingerências público-municipal-governamentais, como, também, por conta da arquitetura relacional-mental-social insustentável de descaso para com os animais.

A ONG se configura como campo de atuação do Terceiro Setor, no entanto, ainda que o Instituto se enquadre nessa categoria, o objetivo central da pesquisa não foi analisar este objeto. A questão principal foi compreender como uma ONG de proteção animal e socioambiental interfere-remodela o design cognitivo político-social em relação à vertente do cuidado e do respeito à existência dos animais, possibilitando o desenvolvimento e o crescimento humanitário a partir da preocupação e da assistência aos animais retirados dos espaço-sócio-histórico-políticos do abandono.

Por abandono, a análise a que se chega é a de que é uma das formas mais concretas de violência e que esta é uma cristalização societário-cultural presente não somente em Porto Seguro, mas em todo o Brasil, bem como em outras partes do Mundo.

O Instituto a Voz dos Bichos luta contra a cultura do abandono dos animais, com a função de desconstruir o design-arquitetura insustentável que concebe o animal como objeto-coisificação. Esta concepção coaduna com o fato de que, atualmente, enfrenta-se uma violência de toda ordem na sociedade, sejam homicídios, assaltos, bullying, agressões contra mulheres e crianças, entre outros. São tantas as questões envolvendo o assunto que as autoridades, a sociedade em geral e as instituições têm se debruçado para combater ou ao menos minimizar o problema, sem muito sucesso. Assim, com a atenção voltada para a violência contra os seres humanos, esquece-se da violência contra os animais, talvez, a mais 
covarde e inaceitável de todas as formas de violência. Ocorrem situações extremas no dia a dia, pois, se por um lado existem animais bem tratados por pessoas que lhes proporcionam uma vida de carinho, amor, abrigo e até luxos desnecessários, por outro lado há animais abandonados nas ruas, passando necessidades e submetidos a abusos e maus tratos. Ao mesmo tempo em que são vítimas de atropelamentos e de crueldade, animais abandonados representam um grave problema de saúde pública, uma vez que são os principais reservatórios e transmissores de zoonoses como raiva e leishmaniose visceral, configurando-se em importante questão ambiental ${ }^{2}$.

Dentre os papéis do Instituto, é importante destacar que ele contribui para sanar possíveis doenças de origem zoonose-sanitária e educar ambientalmente. Além disso, possibilita a consciência/sensibilização do elemento social-humano no tangente ao cuidado com os animais, propiciando, dessa forma, não somente a qualidade de vida dos animais recuperados, mas, essencialmente, o desenvolvimento humanístico, por meio de campanhas virtuais ou em espaços públicos da cidade para a divulgação das ações, feiras de adoção e cuidados médico-veterinários.

Acerca das Zoonoses, cabe apresentar o que afirma Kimura (in Andrade e Oliveira, 2002):

Zoonoses são enfermidades transmitidas naturalmente dos animais ao homem. Apesar dos avanços verificados no seu controle, a incidência de zoonoses permanece alta em todos os países em desenvolvimento. Zoonoses emergentes aparecem constantemente como resultado de troca de comportamento de algumas doenças e podem se transformar em ameaças, como a hantavirose.

Ainda no tocante às zoonoses, é importante mencionar o que coloca Brasil (2016):

Para qualquer grupo de zoonoses, as ações, as atividades e as estratégias de vigilância, prevenção e controle de zoonoses executadas pela área de vigilância de zoonoses se pautam em atuar e intervir, direta ou indiretamente, sobre as populações de animais alvo, de modo a refletir em benefício direto (quanto à redução ou eliminação, quando possível, do risco iminente de transmissão de zoonose) à saúde da população humana.

\footnotetext{
${ }^{2}$ Informação retirada do artigo "ABANDONO E MAUS TRATOS CONTRA ANIMAIS: ASPECTOS SOCIAIS AMBIENTAIS E LEGAIS”, de Karollyna Lagares de SOUZA e Maria Izabel Barnez PIGNATA no site: https://www.cepae.ufg.br/up/80/o/TCEM2014-Biologia-KarollynaLAgaresSouza.pdf. Acesso em 27 de setembro de 2017.
} 
O Instituto enfrenta dificuldades para seguir atuando no município, mas, mesmo sem o apoio necessário, desenvolve ações que, em longo espectro, beneficiam toda a sociedade. Dentre as ações executadas, as principais aparecem no quadro, a seguir:

Quadro 2 - Principais ações executadas pelo Instituto A Voz dos Bichos.

\begin{tabular}{|c|c|}
\hline 1. & Acolhimento dos animais resgatados. \\
\hline 2. & $\begin{array}{l}\text { Cuidados médico-veterinários aos animais recolhidos e aos animais de pessoas } \\
\text { com dificuldades financeiras que procuram o Instituto. }\end{array}$ \\
\hline 3. & $\begin{array}{l}\text { Ajuda em serviços como consultas, exames e aplicação de vacinas aos animais } \\
\text { cujos donos não possuem poder alto aquisitivo. }\end{array}$ \\
\hline 4. & Campanhas de conscientização da população para a adoção responsável. \\
\hline 5. & $\begin{array}{l}\text { Sensibilização do elemento humano para a proteção e para o cuidado dos } \\
\text { animais domésticos. }\end{array}$ \\
\hline
\end{tabular}

Fonte: Informações fornecidas pelo Instituto A Voz dos Bichos.

As ações executadas pelo Instituto alcançam dimensões socioambientais, pois, com a retirada de gatos e cães das ruas, dentre outros animais, além de contribuir para melhores condições de vida dos animais recolhidos, a ONG possibilita a higiene sanitária das ruas, propiciando a diminuição de doenças transmitidas por animais desassistidos de vacinas e de cuidados veterinários.

O papel do Instituto transcende as noções de profilaxia dos espaços públicos, pois o referido órgão desenvolve campanhas de conscientização e sensibilização da população, fomentando conhecimentos sobre a importância da adoção de animais, acerca dos problemas advindos da proliferação de animais sem os cuidados médicos na geografia urbana, com isso, possibilitando processos de humanização do próprio ser humano. 


\section{MARCO TEÓRICO UTILIZADO PARA A COMPREENSÃO DO FENÔMENO INVESTIGADO}

Para a investigação das contribuições do Instituto a Voz dos Bichos no tangente à proteção animal e socioambiental foi imprescindível recorrer a um marco teórico múltiplo, alicerçado, pelo menos, em três áreas e vertentes do conhecimento: social, ambiental e política. Ademais, para a compreensão do fenômeno foi importante ampliar os conceitos de projeto social, socioambiental, papel desempenhado pelas ONGs no Brasil, Políticas públicas e Terceiro setor, além de outros conceitos.

Por pesquisa multidisciplinar e multirreferencial, levou-se em consideração o seguinte: quando as ciências humanas perdem a ambição de retirar de cada um dos setores da atividade humana as leis que a caracterizam e se orientam mais para um procedimento de resolução de problemas, isso as conduz a se inquietarem com as divisões que poderiam restringir sua ação, especialmente as fronteiras disciplinares, com seus territórios reservados (os historiadores ocupam-se do passado; os sociólogos do presente; os geógrafos do espaço; etc.), pois isso poderia ser um obstáculo à compreensão completa de um problema sob todos os seus aspectos e as inter-relações entre eles (LAVILLE e DIONNE, 2007, p. 44).

O marco teórico multirreferencial ancorou-se em teóricos como Boff e sua discussão do saber cuidar, sustentabilidade, a águia e a galinha como metáfora da condição humana; Morin, a partir da ética e da necessidade da compreensão do humano; Guattari e a noção das três ecologias; Barthes, sob a ótica de que a literatura comporta todos os saberes; Capra e a noção sobre o ponto de mutação; Montaño e sua discussão em torno do Terceiro Setor; Leff e suas teses em torno do saber e da racionalidade ambiental, além de teóricos que discorrem diretamente sobre projetos socioambientais.

Antes de qualquer aporte teórico acerca do fenômeno investigado, faz-se oportuno discorrer um pouco sobre a relação animal racional, animal irracional e como isso foi possível.

Sabe-se que ao longo das formações sociais, no mundo inteiro, as relações de aproximação entre homem e animal foram se constituindo com a aprendizagem e convivência de ambos os lados. Em relação aos gatos, por exemplo, a aproximação, segundo Rodrigues (2014), deu-se da seguinte maneira: 
O gato foi o primeiro vigia de estoque. Foi assim: há 10 mil anos, as primeiras colheitas atraíram ratos pela primeira vez. Para sorte dos primeiros agricultores, no rastro dos roedores veio seu predador, o Felis silvestris. O gato selvagem era um bicho meio arisco, mas mantinha os ratos longe dos celeiros, e o contrato foi fechado. Aos poucos, a relação deixou de ser somente profissional: em 9500 a. C., um homem e seu gato foram enterrados juntos no Chipre. E, após milênios de bembom, criamos uma subespécie, Felis silvestriscatus, o chamado gato doméstico. Que não é tão doméstico assim. O autor de Cat sense explica: "Para serem eficazes contra os ratos, os gatos precisaram manter muitos de seus instintos selvagens".

Some-se ao que se afirmou acima, a noção de cuidado de Boff (2013, p. 14), quando ele pontua o seguinte:

Sonhamos com uma sociedade mundializada, na grande casa comum, a Terra, onde os valores estruturantes se construirão ao redor do cuidado com as pessoas, sobretudo com os diferentes culturalmente, com os penalizados pela natureza ou pela história, cuidado com os espoliados e excluídos, as crianças, os velhos, os moribundos, cuidado com as plantas, com os animais, as paisagens queridas e, especialmente, cuidado com a nossa grande e generosa Mãe, a Terra. Sonhamos com o cuidado assumido como o ethos fundamental do humano e como compaixão imprescindível para com os seres da criação.

Fundamentando-se na vertente do cuidado, também é possível fazer ponte com a ecologia da ação como elemento necessário para a ética da existência e, com respeito a isso, Morin (2011, p. 41) traz a seguinte contribuição:

A ecologia da ação indica-nos que toda ação escapa, cada vez mais, à vontade do seu autor na medida em que entra no jogo das inter-retro-ações do meio onde intervém. Assim a ação corre o risco não somente de fracassar, mas também de sofrer desvio ou distorção de sentido.

O pensamento Moraniano possui relação direta com o jogo de responsabilidades entre sociedade e poder público, pois, ora a sociedade se comporta de forma irresponsável do ponto de vista da ética em relação aos animais domésticos, seres indefesos que precisam dos cuidados humanos, ora, a gestão pública silencia, passando a responsabilidade para a comunidade.

Esse quadro de descaso faz parte de uma arquitetura mental societária nociva e desrespeitosa a todas as formas de vida, fruto da inconsciência ou negligência dos efeitos 
colaterais da não ação, do desligamento com o meio ambiente do qual a humanidade é parte integrante. A respeito desta questão, Morin (2011, p. 32) discorre sobre como tudo existe em rede e para a necessidade de uma consciência ética trinitária - indivíduo-sociedade-espécie, apresentando motivos para que todos busquem o religare e a sensibilidade para o cuidado em relação a todos os seres que habitam o planeta:

Num minúsculo planeta perdido, feito de um agrado de detritos de uma estrela desaparecida, fadada aparentemente às convulsões, tormentas, erupções, terremotos, a vida surgiu como uma vitória inusitada nas virtudes da religação. Um turbilhão interligando macromoléculas, gerando a sua própria diversidade ao integrá-la à sua unidade, teria criado a partir de si mesmo, uma organização de complexidade superior: uma auto-eco-organização, de onde emergiram todas as qualidades e propriedades da vida.

A partir da teoria da complexidade de Morin, pode-se perceber que tudo está interligado e, dessa forma, há a chance de enfraquecimento da visão utilitária que o ser humano, muitas vezes, possui sobre os animais.

Nessa visão reducionista utilitária em sociedades altamente dependentes da pecuária para o desenvolvimento interno, é perigosa a estrutura cognitiva do cuidado, pois vem travestido de interesse capital para o abate ou para outras finalidades culturalmente aceitas para o uso do animal com fins de aumento na balança comercial.

Consoante aos animais domésticos é recorrente o discurso entre os membros da sociedade brasileira, em especial, em relação aos cidadãos que ainda não atingiram a concretude da fase das necessidades fisiológicas, uma ausência total no tocante ao cuidado com os animais, partindo-se sempre do pressuposto de que se os animais não dão lucro não são importantes.

Ainda com respeito à complexidade, tomando como referência Capra (2012, p. 21), tem-se o seguinte:

As últimas duas décadas do século XX vêm registrando um estado de profunda crise mundial. É uma crise complexa, multidimensional, cujas facetas afetam todos os aspectos de nossa vida - a saúde e o modo de vida, a qualidade do meio ambiente e das relações sociais, da economia, tecnologia e política. É uma crise de dimensões intelectuais, morais e espirituais; uma crise de escala e premência sem precedentes em toda a história da humanidade. 
No que tange à ótica insustentável das relações utilitárias, é importante analisar o que coloca Leff (2001, pp. 448-449):

\begin{abstract}
Toda ética é uma ética da vida. A ética do desenvolvimento sustentável, muito mais do que um "jogo de harmonização" de éticas e racionalidades implícitas no discurso do "desenvolvimento sustentável" (do mercado, do Estado, da cidadania) e da inclusão do ethos das diferentes culturas, implica a necessidade de conjugar um complexo de princípios básicos dentro de uma ética do bem comum e da sustentabilidade. E isso leva a transgredir a ética implícita na racionalidade econômica e instrumental que se incorporou no ser humano moderno e que são antitéticas ao propósito da sustentabilidade. Estas racionalidades tornaram-se irracionais ao cristalizarem-se em crenças e condutas refletidas e em comportamentos insustentáveis.
\end{abstract}

Do ponto de vista do papel social desempenhado pela ONG, faz-se importante trazer à tona alguns conceitos que serão cruciais para a compreensão do contexto no qual se insere o Instituto objeto de estudo. Dentre os campos conceituais, aparecem: Terceiro Setor, Gestão social e o de ONG, pois, a partir disso, será possível entender, com mais profundidade, a importância desempenhada/exercida pelo Instituto na cidade.

É oportuno sinalizar que o conceito de Terceiro Setor é complexo e exige aportes em vários teóricos, bem como é necessário mencionar que, para entendê-lo, em minúcias, faz-se imprescindível conhecer as terminologias ONG e Movimentos sociais, pois estão interligados.

Para a compreensão do que seria ONG, pode-se recorrer a Montaño (2003, pp. 14-15) quando afirma que:

A relevância do tema é forte. Por um lado, caracteriza um fenômeno que envolve um número significativo de organizações e instituições - organizações não governamentais (ONGs), sem fins lucrativos (OSFL), instituições filantrópicas, empresas "cidadãs", entre outras - e sujeitos individuais - voluntários ou não.

Já a compreensão do conceito de Terceiro Setor exige conhecimento e leitura ao redor de campos teórico-conceituais como limites de atuação do Estado, Estado Neoliberal, surgimento da noção de Estado Mínimo, pois, segundo Montaño, o Terceiro Setor, muitas vezes, confunde-se no âmbito do público-privado. 
O fato é que, tanto a partir de Montaño como de vários teóricos que aprofundaram estudos em torno do tema em baila, o Terceiro Setor surge de lacunas deixadas pelo Estado. No caso do Instituto A Voz dos Bichos, essa noção fica bastante evidente, pois a ONG, como já fora apresentado, surgiu a partir da ineficiência ou da ausência de políticas públicas da gestão municipal e da sociedade no tocante aos animais domésticos abandonados na cidade.

Essa ausência de políticas públicas, com a presença apenas de um Controle de Zoonoses, órgão deveras recente no município de Porto Seguro e pouco efetivo, com sérias limitações e de baixo espectro geográfico de atuação, causa sérios danos, a curto e longo prazo, à sociedade. Esses danos, muitas vezes, passam despercebidos, já que os cidadãos, quase sempre, estão envoltos em e por questões particulares de existência-trabalhoeconômico-financeira. Nesse sentido, pode-se mencionar que mesmo aqueles cidadãos mais ativos que concebem desenvolvimento para além dos conceitos e concepções da economia clássica, no máximo, lutam por justiça social, sem a dimensão da necessidade de uma justiça socioambiental. Desconhecem que jamais haverá justiça social sem que, antes, ocorra uma justiça ambiental. Não compreendem que as degradações ambientais e, com elas, a destruição de outras formas de vida além da humana, provocam desequilíbrios diretos na sociedade, desencadeando injustiças sociais em campos diversos. Essa falta de visão políticosocial-ecológico-histórica impossibilita a descristalização e a desconstrução das raízes culturais do abandono que interferem, diretamente, nas questões de saúde pública.

Também não é possível deixar de considerar que o abandono de animais urbanos pode causar problemas de saúde pública, de segurança e mesmo impacto ambiental, a atuação do poder público, em parceria com Organizações Não Governamentais (ONGs) e Associações, deveria ter como objetivos: direcionar recursos para o tratamento dos animais; fiscalizar, juntamente com a polícia ambiental, seus cuidados; criar um cadastro; construir abrigos para os animais abandonados; fazer feiras de doação de animais recolhidos; e conscientizar a adoção por parte da comunidade. É importante destacar que a falta de uma política pública específica pode gerar, além dos problemas mencionados, gastos desnecessários ao município com recolhimento, vacinas e outros medicamentos, alimentação e abrigo, já que o animal é devolvido às ruas sem controle. Contudo, se o município, juntamente com a comunidade e com as ONGs e Associações, desenvolvesse projetos ambientais e educacionais para solucionar o problema em questão, haveria uma redução de gastos municipais associados à diminuição do abandono de animais. Existindo 
políticas públicas direcionadas para os animais urbanos e havendo também uma fiscalização para o cumprimento das mesmas, não haveria gastos equivocados com a manutenção das ruas e do meio ambiente ${ }^{3}$.

$\mathrm{Na}$ esfera de ausências há paradoxos que precisam ser amplamente discutidos. $\mathrm{O}$ abandono, fruto da inércia e da falta de compromisso com as outras formas de vida, desencadeia uma série de zoonoses, comprometendo, consequentemente, o meio ambiente. Em meio a tudo isso, a população omissa a quase tudo em relação ao cuidado com os animais, no máximo, cobra responsabilidades do poder público local. Nesse sentido, ainda é oportuno esclarecer que tudo faz parte de uma arquitetura mental de descaso aos animais que, com certeza, encontra explicações no processo de formação da nacionalidade brasileira, em questões religioso-culturais insustentáveis e nos aspectos econômico-sociais.

Apresentada a perspectiva capitalística criticada por Guattari, pode-se passar ao que se entende por Gestão social e, sobre esse campo, pode-se recorrer a Fernando G. Tenório (RAP, v. 32: 07-23) por meio da noção de que o tema Gestão Social tem sido evocado, nos últimos anos, para acentuar a importância das questões sociais para os sistemas de governo, sobretudo, para a implantação de políticas públicas, assim como dos sistemas-empresa no gerenciamento de seus negócios. Nesse campo de visada, trata-se de justificar a presença do Estado mínimo na atenção focalizada, através de políticas sociais e, ao mesmo tempo, flexibilizar as relações de trabalho e de produção de agentes econômicos.

Acerca do conceito de Movimentos Sociais, Gohn (2013, p. 13) coloca em discussão que: “(...) desde logo, é preciso demarcar nosso entendimento sobre o que são movimentos sociais: nós os vemos como ações sociais coletivas de caráter sociopolítico e cultural que viabilizam distintas formas da população se organizar e expressar suas demandas." Nessa concepção, pode-se dizer que o Instituto a Voz dos Bichos nasceu de carências e gritos sociais em relação aos animais, seres explorados pelo modelo capital e, ao mesmo tempo, relegados ao extermínio.

\footnotetext{
${ }^{3}$ Fragmento textual extraído do texto "POLÍTICAS PÚBLICAS DE PROTEÇÃO E DEFESA DOS ANIMAIS URBANOS: O CASO DE SAPUCAIA DO SUL (RS)", de Larice da Silva e Angélica Massuquetti, publicado no $7^{\circ}$ ENCONTRO DE ECONOMIA GAÚCHA, Sessão Temática: J. Meio Ambiente de Desenvolvimento Sustentável. Informação encontrada no site https://www.fee.rs.gov.br/wp-content/uploads/2014/05/201405267eeg-mesa24politicaspublicasprotecaodefesaanimaispublicas.pdf. Acesso em 27 de setembro de 2017.
} 
O papel social desempenhado pelo Instituto propicia uma mudança mental social rumo à sustentabilidade e, nesse âmbito, acerca da necessidade de outra arquitetura mental humana, é possível recorrer ao que Boff (2012, p. 120) afirma:

Até o presente momento, o sonho do homem branco é dominar a Terra e submeter todos os demais seres. Esse sonho se transformou num pesadelo. Como nunca antes, o apocalipse pode ser realizado por nós mesmos. Por isso impõe-se uma reconstrução de nossa humanidade e de nossa civilização para que seja sustentável no sentido de restabelecer o pacto natural com a Terra, e considerar todos os demais seres, verdadeiramente como irmãos e irmãs, e assim devem ser tratados.

O domínio dos limites de atuação da gestão pública em relação às questões de zoonose é importante para a dimensão do quadro operante em torno desse fenômeno na cidade e, nesse sentido, percebe-se que há déficits na atuação pública, pois, no município, todavia, não há um órgão público consolidado para tratar dos problemas relacionados à retirada e cuidado dos animais. Diante desse quadro, o Instituto A Voz dos Bichos ganha ainda mais importância, haja vista que preenche vazios no que concerne à retirada de animais abandonados nas ruas de Porto Seguro com promoção da saúde e bem-estar socioambiental, tanto para a população como para o animal doméstico acolhido.

\section{ANÁLISE QUALITATIVO-QUANTITATIVA DAS AÇÕES DO INSTITUTO A VOZ DOS BICHOS}

Um dos objetivos da pesquisa foi mapear as ações desenvolvidas pelo Instituto desde o ano de criação até 2017, mas, infelizmente, isso não foi possível devido ao fato de que por ausência de apoio da sociedade e da gestão pública municipal, a Instituição atua no limite das possibilidades. Diante desses déficits, com a falta pessoal de apoio administrativo para o cadastro de dados, nem tudo está registrado. Como não foi possível um registro de todas as ações, no Quadro 3, serão apresentadas parte de tudo o que já foi feito, além de projetos em andamento ou em proposição. 
Quadro 3 - Intervenções diretas e ações concretas do Instituto desde o ano de fundação até 2017.

\begin{tabular}{|c|c|}
\hline Castrações & Há uma média de 30 por mês; \\
\hline $\begin{array}{l}\text { Cirurgias de } \\
\text { complexidade }\end{array}$ & $\begin{array}{l}\text { Na média, é feita uma por mês, sendo que há meses nos quais, por } \\
\text { falta de verba, tais procedimentos tornam-se quase impossíveis, } \\
\text { mas, em compensação, há meses nos quais são feitos mais de um } \\
\text { processo, propiciando a média de uma cirurgia de complexidade por } \\
\text { mês ao ano. }\end{array}$ \\
\hline $\begin{array}{l}\text { Procedimentos } \\
\text { pós-resgate }\end{array}$ & $\begin{array}{l}\text { Todo animal resgatado passa por uma análise clínica antes de ser } \\
\text { levado para adoção. Até que isso ocorra, o animal fica com } \\
\text { colaboradores e a média de gastos com um animal sadio, até que } \\
\text { seja adotado, gira em torno de quinhentos reais (considerando } \\
\text { consultas, vacinas, remédios, vitaminas, ração e castração). }\end{array}$ \\
\hline Outras ações & $\begin{array}{l}\text { As principais ações desenvolvidas desde } 2011 \text { até } 2017 \text { foram as } \\
\text { seguintes: feira de adoção na Praça do Relógio, periódica a cada } 03 \\
\text { meses; feira de adoção todo sábado no mercado municipal (Esse } \\
\text { projeto foi implantado tendo como foco principal os gatinhos, haja } \\
\text { vista que são mais fáceis de transportar, além do fato de que há uma } \\
\text { população muito grande de felinos nas ruas e no Instituto; pet dia } \\
\text { feliz. Trata-se de um projeto para arrecadar dinheiro, em parceria } \\
\text { com a pizzaria Bárbara, na Praça do Relógio; nesse mesmo dia, há a } \\
\text { colaboração do McDonald's. Nessa mesma data, também é realizado } \\
\text { um bingo, com a finalidade de chamar mais participantes e, } \\
\text { igualmente, arrecadar dinheiro; café colonial.). }\end{array}$ \\
\hline
\end{tabular}

Fonte: Dados apresentados pelo Instituto A Voz dos Bichos. 


\section{ABRANGÊNCIA E VISIBILIDADE DO INSTITUTO A VOZ DOS BICHOS}

Ao longo do mês de março de 2015, foram aplicados cinquenta questionários a cinquenta moradores de Porto Seguro, com o objetivo de captar a dimensão da atuação do Instituto na cidade e como este contribui para a mudança na mentalidade da população em relação ao cuidado com os animais e com o meio ambiente.

Os questionários semiestruturados foram elaborados a partir das seguintes perguntas: Idade? Conhece o Instituto A Voz dos Bichos? Caso conheça o Instituto, sabe quais são os seus objetivos, finalidades e campo de atuação? Como conheceu o Instituto A Voz dos Bichos? Já adotou algum animal do Instituto? Já contribuiu de alguma forma com o Instituto? Conhece a página do facebook do Instituto? O que acha da atuação do Instituto na cidade? A partir de seu conhecimento acerca do Instituto, qual a sua opinião a respeito da própria responsabilidade e responsabilidade da gestão pública em relação aos animais abandonados na cidade?

Com base na análise das respostas apresentadas pelos entrevistados, todos moradores locais, chegou-se aos resultados expressos nos quadros 4 e 5, abaixo:

Quadro 4 - Idade

\begin{tabular}{|c||c|}
\hline Quantitativo de pessoas & Faixas etárias \\
\hline \hline 5 & Entre 15 e 17 anos \\
\hline \hline 5 & Entre 18 e 20 anos \\
\hline \hline 12 & Entre 21 e 25 anos \\
\hline \hline 18 & Entre 26 e 33 anos \\
\hline \hline 5 & Entre 34 e 41 anos \\
\hline \hline 5 & De 42 anos em diante \\
\hline \hline
\end{tabular}

Fonte: Respostas dos questionários aplicados na pesquisa. 
Quadro 5 - Conhece o Instituto A Voz dos Bichos?

\begin{tabular}{|c|c|}
\hline Conheciam & Não conheciam \\
\hline \hline 17 & 33 \\
\hline
\end{tabular}

Fonte: Respostas dos questionários aplicados na pesquisa.

Quadro 6 - Dos que conhecem o Instituto, quantos conheciam quais são os objetivos, finalidades e campo de atuação da ONG.

\begin{tabular}{|c||c|}
\hline $\begin{array}{l}\text { Conheciam quais são os objetivos, } \\
\text { finalidades e campo de atuação da ONG }\end{array}$ & $\begin{array}{l}\text { Não conheciam quais são os objetivos, } \\
\text { finalidades e campo de atuação da ONG }\end{array}$ \\
\hline \hline 12 & 5 \\
\hline
\end{tabular}

Fonte: Respostas dos questionários aplicados na pesquisa.

Quadro 7 - A forma como as 17 pessoas conheceram o Instituto A Voz dos Bichos.

\begin{tabular}{|c||c|}
\hline \multicolumn{1}{|c||}{ Quantitativo } & Forma \\
\hline \hline 5 & $\begin{array}{c}\text { A partir da comunidade do Instituto no } \\
\text { facebook. }\end{array}$ \\
\hline \hline 6 & $\begin{array}{c}\text { Tiveram contato em feiras e campanhas } \\
\text { de adoção pela cidade. }\end{array}$ \\
\hline \hline 6 & $\begin{array}{c}\text { Conheceram a partir de amizades que } \\
\text { adotaram animais no Instituto. }\end{array}$ \\
\hline
\end{tabular}

Fonte: Respostas dos questionários aplicados na pesquisa 
Das 17 pessoas que conheciam o Instituto, ao serem indagadas sobre se já haviam adotado algum animal, nenhuma havia adotado e todas responderam que, futuramente, pretendiam adotar algum animal. Em relação à pergunta sobre se contribuíam, de alguma forma, para o Instituto, todas responderam que não e 5 pessoas disseram que pretendiam fazê-lo em breve. Por fim, como mencionado, somente cinco pessoas conheciam a página do Instituto no facebook e, das 17 pessoas que conheciam o Instituto, 13 pessoas disseram que o Instituto exerce um papel importantíssimo para a retirada de animais das ruas, oferecendo cuidados médicos veterinários e contribuindo para a profilaxia de possíveis doenças transmitidas por animais pelas ruas da cidade. Ademais, dos cinquenta entrevistados, somente 23 pessoas assumiram que a responsabilidade pelo cuidado em relação aos animais domésticos abandonados nas ruas de Porto Seguro era de responsabilidade conjunta população-poder público, 3 entrevistados não souberam opinar e 24 pessoas disseram que a responsabilidade era única e exclusivamente do poder público.

\section{ALGUMAS CONSIDERAÇÕES FINAIS}

Ao longo da pesquisa foi possível perceber que a cultura-ação do descaso para com os animais que não servem à perspectiva capital do lucro pode e deve ser combatida, pois o ser humano precisa desvencilhar-se dessa imagética das relações utilitárias.

A cultura insustentável do abandono demanda mudanças culturais urgentes na relação humana-animal e, a cerca dessa problemática, ou seja, da necessidade de uma nova arquitetura de relações, torna-se oportuno recorrer ao que Guattari (1990, p. 33) assevera:

\footnotetext{
A ecologia social deverá trabalhar na reconstrução das relações humanas em todos os níveis, do socius. Ela jamais deverá perder de vista que o poder capitalista se deslocou, se desterritorializou, ao mesmo tempo em extensão - ampliando seu domínio sobre o conjunto da vida social, econômica e cultural do planeta - e em "intenção" - infiltrando-se no seio dos mais inconscientes estratos subjetivos. Assim sendo, não é possível pretender opor-se a ele apenas de fora, através de práticas sindicais e políticas tradicionais. Tornou-se igualmente imperativo encarar seus efeitos no domínio da ecologia mental, no seio da vida cotidiana individual, doméstica, conjugal, de vizinhança, de criação e de ética pessoal. Longe de buscar um consenso cretinizante e infantilizante, a questão será, no futuro, a de cultivar o dissenso e a produção singular de existência. A subjetividade capitalística, tal como é engendrada por operadores de qualquer natureza ou tamanho, está manufaturada de modo a premunir a existência contra toda intrusão de
} 
acontecimentos suscetíveis de atrapalhar e perturbar a opinião. Para esse tipo de subjetividade, toda singularidade deveria ou ser evitada, ou passar pelo crivo de aparelhos e quadros de referência especializados. Assim, a subjetividade capitalística se esforça por gerar o mundo da infância, do amor, da arte, bem como tudo o que é da ordem da angústia, da loucura, da dor, da morte, do sentimento de estar perdido no cosmos...

Ao longo da pesquisa corroborou-se que o abandono de animais em Porto Seguro se configura como uma crise de ética humanitária e, nesse aspecto, Boff (2013, p. 64) dialoga com Morin ao esclarecer que: "A ética, portanto, desinstala a moral. Impede que ela se feche sobre si mesma. Obriga-a a constante renovação no sentido de garantir a habitabilidade e a sustentabilidade da moradia humana: pessoal, social e planetária".

É crucial destacar que a ONG em questão se consolida como espaço de cura, de cuidado, de afeto e, principalmente, como ponte para um novo olhar sobre todos os seres animais. Além disso, pode-se externar que, mesmo diante de todas as dificuldades financeiras e de pessoal, o Instituto segue firme e se concretiza-estabelece como organização que fomenta a cultura do respeito à pluralidade da existência de todos os seres animais desencadeando a reforma da reforma do pensamento da sociedade de Porto Seguro para com os animais.

A ONG cumpre um dos papéis apregoados por Morin (2003, p. 102) em relação à necessidade de reformar o pensamento da sociedade, o de: - ensinar a cidadania terrena, ensinando a humanidade em sua unidade antropológica e suas diversidades individuais e culturais, bem como em sua comunidade de destino, própria à era planetária, em que todos os animais enfrentam os mesmos problemas vitais e mortais.

O Instituto a Voz dos Bichos, além de todas as melhorias no que concerne à qualidade de vida dos animais, desempenha um papel político de formação da cidadania mostrando à tessitura social a urgência do cuidado e do respeito às variadas forma de vida. Ademais, provoca o despertar da sociedade em relação ao papel da gestão pública municipal para a proteção animal e ambiental. Nesse aspecto, Passos (1979, p. 20) sinaliza que:

Tornam-se, pois, imperiosas e urgentes as providências em favor do meioambiente brasileiro por parte das autoridades responsáveis juntando-se, estas, às boas razões apresentadas pelos ecologistas levando a sério a condição vital do problema e antecipando-se à solução dos incidentes ou dos atentados praticados contra a natureza. 
Por fim, o Instituto exerce influência sobre os imaginários sociais no que concerne à sustentabilidade no campo da ecologia da ação, da ecologia do pensar, da ecologia mental, da ecologia dos sentidos, da ecologia sociopolítica e da ecologia do humano.

\section{REFERÊNCIAS}

BARTHES, Roland. Aula. 14. ed. São Paulo: Editora Cultrix, 1977.

BOFF, Leonardo. A águia e a galinha: uma metáfora da condição humana. 51. ed. Petrópolis, RJ: Vozes, 2013. Sustentabilidade: o que é, o que não é. Petrópolis, RJ: Vozes, 2012.

BRASIL. Manual de vigilância, prevenção e controle de zoonoses: normas técnicas e operacionais. Ministério da Saúde, Secretaria de Vigilância em Saúde, Departamento de Vigilância das Doenças Transmissíveis. - Brasília: Ministério da Saúde, 2016.121 p.

CAPRA, Fritjof. O ponto de mutação. A Ciência, a Sociedade e a Cultura emergente. São Paulo: Cultrix, 2012.

GOHN, Maria da Glória (Org). Movimentos sociais no início do século XXI: antigos e novos atores sociais. 6. ed. Petrópolis, RJ: Vozes, 2013.

GUATTARI, Félix. As três ecologias. Campinas, SP: Papiro, 1990.

KIMURA, Leda Maria Silva. Principais zoonoses. In: ANDRADE, A., PINTO, SC., OLIVEIRA, RS., (orgs). Animais de Laboratório: criação e experimentação [online]. Rio de Janeiro: Editora FIOCRUZ, 2002. 388 p. ISBN: 85-7541015-6.

LAVILLE, Christian. DIONNE, Jean. A construção do saber: manual de metodologia da pesquisa em ciências humanas. Porto Alegre: Artmed; Belo Horizonte: Editora UFMG, 1999.

LEFF, Enrique. Saber Ambiental. Sustentabilidade, Racionalidade, Complexidade, Poder. Petrópolis, RJ: Vozes/PNUMA, 2001.

MONTAÑO, Carlos. Terceiro setor e questão social: crítica ao padrão emergente de intervenção social. São Paulo: Cortez, 2003.

MORIN, Edgar. A cabeça bem-feita: repensar a reforma, reformar o pensamento. 8. Ed. Rio de Janeiro: Bertrand Brasil, 2003.

MORIN, Edgar. O método: ética. V. 6. 4. ed. Porto Alegre: Sulina, 2011.

PASSOS, Claribalte. Ecologia: o homem no rumo da sobrevivência. Recife: Editora Universitária da UFPE, 1979.

RODRIGUES, Alexandre. Como os gatos veem o mundo. Revista SuperInteressante, 2014. Acesso em 19 de março de 2015.

TENÓRIO, Fernando G. Gestão social: uma perspectiva conceitual. Revista da Administração Pública Rio de Janeiro, Fundação Getúlio Vargas. V. 32, nº 5, set./out. 1998, p. 07-23. 